\title{
Step Excrescence Effects for Manufacturing Tolerances on Laminar Flow Wings
}

\author{
Aaron Drake ${ }^{1}$, Anne M. Bender ${ }^{2}$ and Andrea J. Korntheuer ${ }^{3}$ \\ Northrop Grumman Corporation, El Segundo, CA 90245 \\ Russell V. Westphal ${ }^{4}$ \\ California Polytechnic State University, San Luis Obispo, CA 93407 \\ Beverley J. McKeon ${ }^{5}$ and Sergiy Gerashchenko ${ }^{6}$ \\ California Institute of Technology, Pasadena, CA 91125 \\ and \\ Wayne Rohe ${ }^{7}$ and Gary Dale ${ }^{8}$ \\ U.S. Air Force Research Laboratory, Wright-Patterson AFB, OH 45433
}

\begin{abstract}
Manufacturing tolerances for laminar flow wings can be significantly tighter than those of conventional aircraft. The tighter tolerances can significantly affect the assessment of the practicality of designing for laminar flow. However, existing data on the effects of excrescences typical of manufacturing process are limited. Further, information on the effects - often beneficial—of pressure gradient present on the laminar flow wings is not generally available. To address these concerns, a series of experiments has been undertaken to examine the effects of surface steps in the presence of pressure gradients. The step geometries were selected to represent those that result from actual aircraft manufacturing processes. The range of pressure gradients correspond to those typical of laminar flow wings. Initial experiments were conducted in a low-speed wind tunnel. Later experiments used a novel propelled-model test facility. The results of these studies show that the allowable sizes of surface excrescences for laminar flow wings may be significantly greater than has conventionally been assumed. This could significantly influence the more widespread use of laminar flow for drag reduction, resulting in more efficient aircraft.
\end{abstract}

\section{Nomenclature}

$\mathrm{C}_{\mathrm{l}} \quad=$ local lift coefficient

$\mathrm{C}_{\mathrm{p}} \quad=$ coefficient of pressure

$\mathrm{K}=$ dimensionless pressure gradient

$\mathrm{k}=$ excrescence height

Re $\quad=$ Reynolds number based on free stream velocity

$\mathrm{Re}_{\mathrm{tr}} \quad=$ transition Reynolds number

$\operatorname{Re}_{\mathrm{k}} \quad=$ excrescence height Reynolds number

$\mathrm{Re}_{\mathrm{kcrit}}=$ critical excrescence height Reynolds number

\footnotetext{
${ }^{1}$ Manager, Flight Analysis, AIAA Senior Member.

2 Aerodynamics Engineer, Aerodynamic Design and Analysis.

${ }^{3}$ Aerodynamics Engineer, Aerodynamic Design and Analysis.

${ }^{4}$ Professor, Mechanical Engineering, AIAA Senior Member.

${ }^{5}$ Assistant Professor of Aeronautics, Graduate Aerospace Laboratories (GALCIT), AIAA Member.

${ }^{6}$ Postdoctoral Scholar, Graduate Aerospace Laboratory (GALCIT), currently Cornell University.

7 Action Officer, AFRL Commander's Action Group.

${ }^{8}$ Lead, Low Speed Configuration Team, Air Vehicles Directorate, AIAA Associate Fellow.
}

American Institute of Aeronautics and Astronautics 


$\begin{array}{ll}\mathrm{Re}_{\mathrm{xk}} & =\text { excrescence location Reynolds number } \\ \mathrm{u}_{\mathrm{e}} & =\text { velocity at boundary layer edge } \\ \mathrm{u}_{\mathrm{k}} & =\text { velocity in boundary layer profile at height } \mathrm{k} \\ \mathrm{x} & =\text { chord-wise distance } \\ v & =\text { kinematic viscosity } \\ v_{\mathrm{e}} & =\text { kinematic viscosity at boundary layer edge } \\ v_{\mathrm{k}} & =\text { kinematic viscosity at height } \mathrm{k}\end{array}$

\section{Introduction}

$\mathrm{U}$

tilizing laminar flow for drag reduction can provide substantial benefits to long-endurance aircraft, such as the SensorCraft concept shown in figure 1. For many such aircraft, skin friction drag is a substantial portion of the overall drag. Designing aircraft surfaces - in particular, wings - to have lower skin friction drag through the control of the boundary layer transition location has been pursued for many decades. The resulting drag reductions possible with such a laminar flow aircraft are often projected to be substantial. However, potential disadvantages associated with incorporating laminar flow wings have prevented the widespread use of this technology to improve aircraft performance, except in a few specialized cases.

Taking advantage of laminar flow on an actual operational aircraft requires overcoming three hurdles to laminar flow: (1) design of the outer mold line (OML) - or, vehicle surface shape - to achieve delayed transition; (2) manufacturing quality of the vehicle surfaces; and (3) operational environment effects. The design of the OML must consider not only the control of boundary layer disturbances to prevent transition from occurring prematurely, but also the impact on the overall vehicle forces and moments. It is not unusual to encounter lower maximum lift coefficients with laminar flow wings, leading to fundamental sizing and design impacts for the overall vehicle. Of concern particularly for tailless aircraft, the pitching moment can be significantly constrained by the design requirements for laminar flow. Once the OML has been designed, actually building the aircraft can be difficult. The required manufacturing tolerances in regions where laminar flow is expected can be significantly tighter than conventional aircraft. However, this is further complicated by the fact that the tolerances needed for laminar flow aircraft are poorly understood. For research or prototype aircraft this can be overcome, but the potential cost impacts in a production program can be prohibitive. Lastly, once a laminar flow aircraft is built, effects of the operating environment, such as surface contamination or maintenance

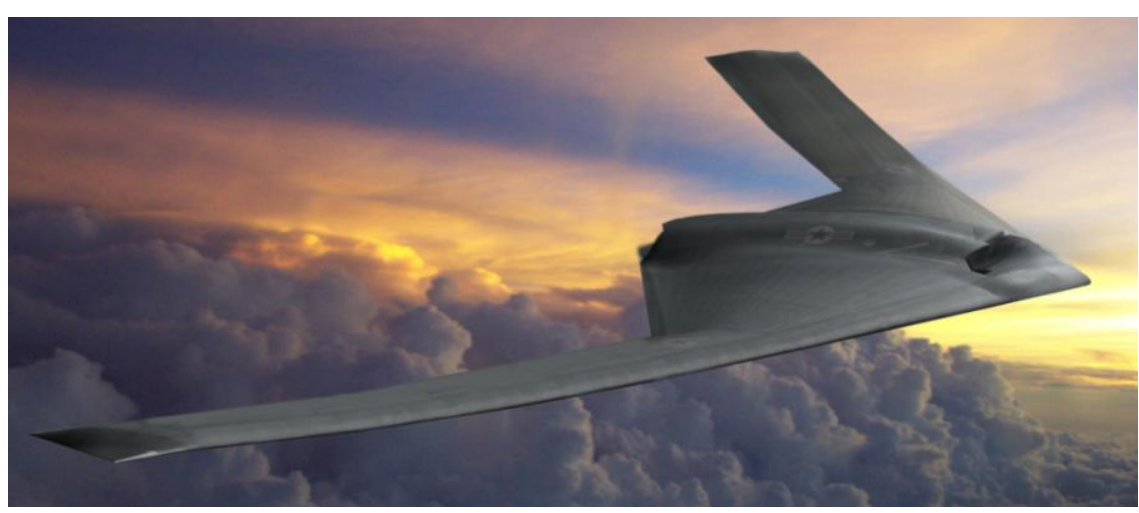

Figure 1. SensorCraft long-endurance concept. effects, can impede actual realization of the laminar flow benefits.

While specifying overly conservative manufacturing tolerances may seem of little consequence since they do not hurt the performance of the aircraft, that is not the case. Having to meet a particular tolerance criteria has profound effects on the design of the tooling and the overall production approach. This, then, has direct implications on not just cost, but production time, field support and aircraft mission availability.

\section{Conventional Approach to Laminar Flow Manufacturing Tolerances}

To address this second hurdle to laminar flow, the building of the vehicle, there is a need to understand excrescence effects and to develop appropriate surface tolerance requirements. Much of the existing literature focuses on excrescences in the absence of a pressure gradient (flat plate flow). As such, the results are not directly applicable to excrescences in pressure gradients on airfoils. ${ }^{1,2}$ Simply applying surface tolerance requirements from the existing literature on flow effects in the absence of a pressure gradient is highly undesirable as the pressure gradient can be expected to have a profound effect on boundary layer transition. Therefore, typically, in order to experimentally develop surface tolerance requirements for a particular aircraft, a wind tunnel model is made of the 
airfoil of interest. ${ }^{3}$ However, in this case, the results are only applicable to that aircraft geometry and are not applicable to any future projects. In cases where it is impractical to do testing specific to the airfoil of interest, existing literature on excrescences on flat plates is typically used.

To address forward-facing steps, there is a significant amount of work in the literature. Work in 1943 by Fage ${ }^{1}$ examined the effects of built-up ridges, essentially an integral forward and aft facing step, 1 inch wide (in the streamwise direction). This low-speed work did not examine forward facing steps in isolation; however, it is valuable to consider since the integrated forward- and aft-facing step should represent a limiting case for the effects of isolated forward-facing steps. The work of Fage did not identify any significant influence of pressure gradientthough this is likely an erroneous conclusion. The results were not expressed in terms of an excrescence height Reynolds number $\left(\operatorname{Re}_{\mathrm{k}}\right)$, as defined in equation 1 .

$$
\operatorname{Re}_{\mathrm{k}}=\mathrm{u}_{\mathrm{k}} \mathrm{k} / \mathrm{v}_{\mathrm{k}}
$$

However, the published data allows a determination of $\mathrm{Re}_{\text {kcrit }}=900$. A summary of a number of experimental data sets was prepared by Braslow in 1960, from which he concluded that 2-D roughness, of the type incorporating an integrated forward and aft facing steps has an $\mathrm{Re}_{\mathrm{kcrit}}$ of approximately 200 . There is, however, significant scatter in the source data, most likely due to varying flow quality in the various facilities used. The value of 200 is near the upper end of the scatter band, as would be appropriate for a flight environment. A low-speed study of 2-D and 3-D surface excrescences by Smith and Clutter ${ }^{5}$ in 1954 concluded that the critical $\operatorname{Re}_{\mathrm{k}}$ for a 2-D wire trip was in the range of 43 to 260 . One of their conclusions was that pressure distribution did not seem to affect the critical $\mathrm{Re}_{\mathrm{k}}$; however, their reported data appears ambiguous on this point.

Flight experiments conducted by Drake, et al. ${ }^{2}$ in 1996 investigated the effects of integral steps and gaps on boundary layer transition in flight on a wing with a favorable pressure gradient designed to mimic that of a laminar flow airfoil. This work was done at Mach numbers of 0.50 to 0.80 . All surface disturbance geometries tested included a forward facing step with an aft facing step one inch downstream. The results of these tests indicated $\mathrm{Re}_{\mathrm{kcrit}}$ values of approximately 500 .

There is very little existing information for isolated aft-facing steps. As such, the best guidance comes from work on wire trips-the mechanism for a wire trip, namely a leeward separation bubble, is likely similar to that of an aft-facing step. However, an aft-facing step is likely to be somewhat worse, due to the lack of boundary layer stabilizing effects from initial compression. From the literature, $\mathrm{Re}_{\text {kcrit }}$ for wire trips is approximately 120. Therefore, aft-facing steps can be expected to have approximately $\mathrm{Re}_{\mathrm{kcrit}}=80$.

Work in 1939 by Hood $^{6}$ examined surface waves on a NACA 23012 airfoil model in a wind tunnel at a $\mathrm{C}_{1}$ of 0.15 . Two wave heights were examined on the 5foot chord model. Chord Reynolds numbers varied up to $10.3 \times 10^{6}$. The primary focus of the work was overall drag of the airfoil and how it was influenced by surface imperfections. However, the key result was that waves in the leading edge region could induce premature

Table 1. Conventional Laminar Flow Tolerances

\begin{tabular}{|cc|}
\hline Excrescence & $\mathbf{R e}_{\text {kcrit }}$ \\
\hline Forward-Facing Step & $\mathbf{1 5 0}$ \\
\hline Aft-Facing Step & $\mathbf{8 0}$ \\
\hline Surface Wave & $\mathbf{2 0 0 0}$ \\
\hline
\end{tabular}
transition, leading to higher skin friction drag.

The waves tested were sinusoidal cross-sections with a streamwise length (width of wave piece) of 3 inches. The critical height for a wave at 10.5 percent chord was 0.020 inches. This corresponds to $\operatorname{Re}_{\text {kcrit }}=3850$. The FalknerSkan pressure gradient parameter $(\beta)$ was -0.006 at the center of the wave. Work by Fage ${ }^{1}$ in 1943 looked at spanwise bulges and their effects on transition locations. Because of the way Fage's bulges were formed, they presented the flow with a wave geometry almost identical to the sinusoidal shape of Hood's experiments. Experiments were carried out in a wind tunnel using both a flat plate (with zero pressure gradient and with imposed pressure gradients) and an airfoil model. One of Fage's conclusions was that the critical size of the wave was essentially independent of the local pressure gradient. Because of the available information, a fairly conservative interpretation is typically used for allowable waves and a value for $\operatorname{Re}_{\text {krit }}$ of 2000 is typical.

$$
\mathrm{K}=\left(v_{\mathrm{e}} / \mathrm{u}_{\mathrm{e}}^{2}\right)\left(\mathrm{du}_{\mathrm{e}} / \mathrm{dx}\right)
$$


Based on the existing literature, recommendations for steps and waves had previously been produced. In the course of producing these recommendations, it became clear that the lack of pressure gradient effect data would result in overly conservative manufacturing tolerance criteria. This is because favorable pressure gradients are known to stabilize boundary layers, thus delaying transition and, likely, permitting a larger excrescence to exist without effect on transition. However, the specifics of these stabilizing effects on laminar flow wings is unknown. Hence, it was necessary to base the criteria on the flat plate (no pressure gradient) data, despite knowing it was conservative. The similar lack of data for adverse pressure gradients was not of as great concern because, in practice for these wing designs, it is generally assumed that boundary layers will transition once the pressure gradient becomes adverse, whether or not an excrescence is present.

For a high-altitude long-endurance aircraft-with typical values of wing chord of approximately $5 \mathrm{ft}$, Mach $=0.60$, altitude $=$ $55,000 \mathrm{ft}$-these tolerance recommendations amount to fairly tight restrictions on the allowable size of excrescences. Figures 2 and 3 show the size of excrescence that would be allowable for this vehicle, based on the flat plate results in the current literature.

Because many aircraft designed for laminar flow will have favorable pressure gradients in the regions of laminar flow, not accounting for the influences of pressure gradient could result in manufacturing tolerances that were overly stringent. However, the effects of pressure gradient are not generally accounted for when defining manufacturing tolerance for laminar flow aircraft. The primary reason for this is a lack of specific information quantifying the relation between pressure gradient and critical excrescence size.

Figure 4 shows an example pressure distribution from an airfoil designed for laminar flow on a high-altitude longendurance vehicle. For a typical cruise conditions, the distribution of dimensionless pressure gradient (K, see equation 2) can be determined for the upper and lower surface, as shown in figures 5 and 6 . These values of pressure gradient are sufficiently high that they would be expected to influence boundary layer transition.

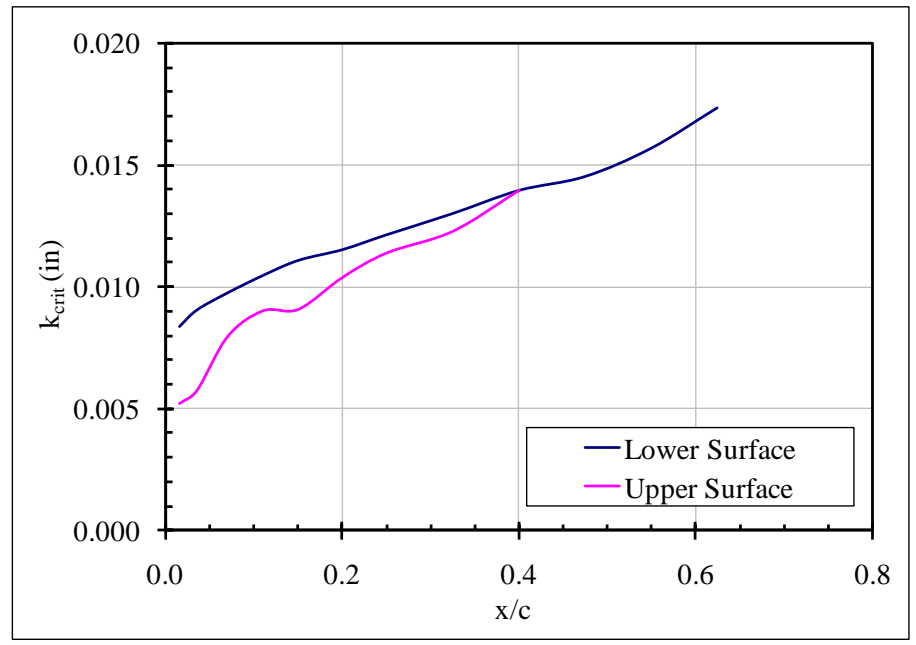

Figure 2. Forward-facing step on a long-endurance aircraft.

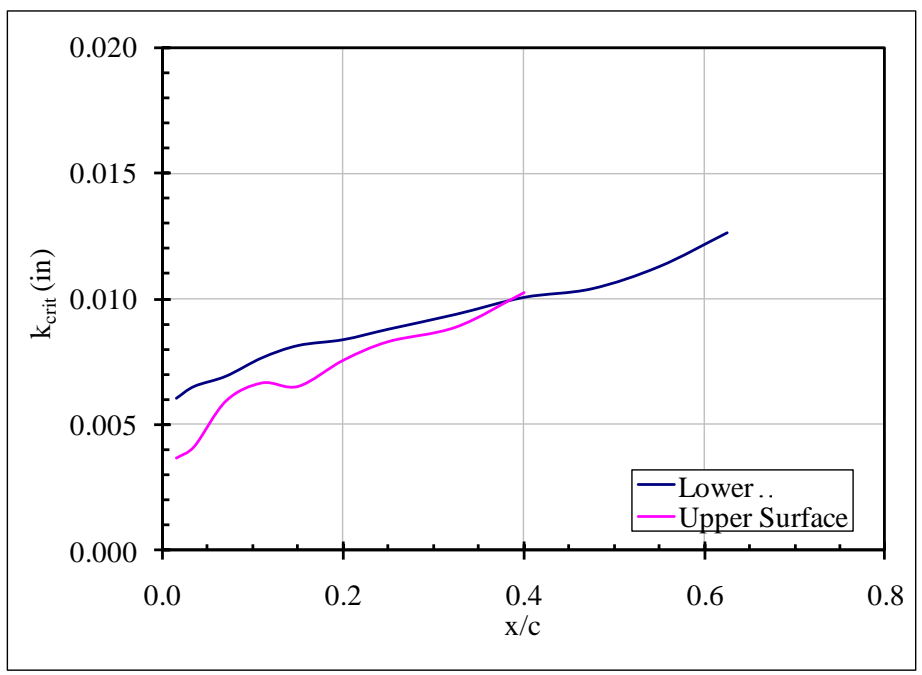

Figure 3. Aft-facing step on a long-endurance aircraft.

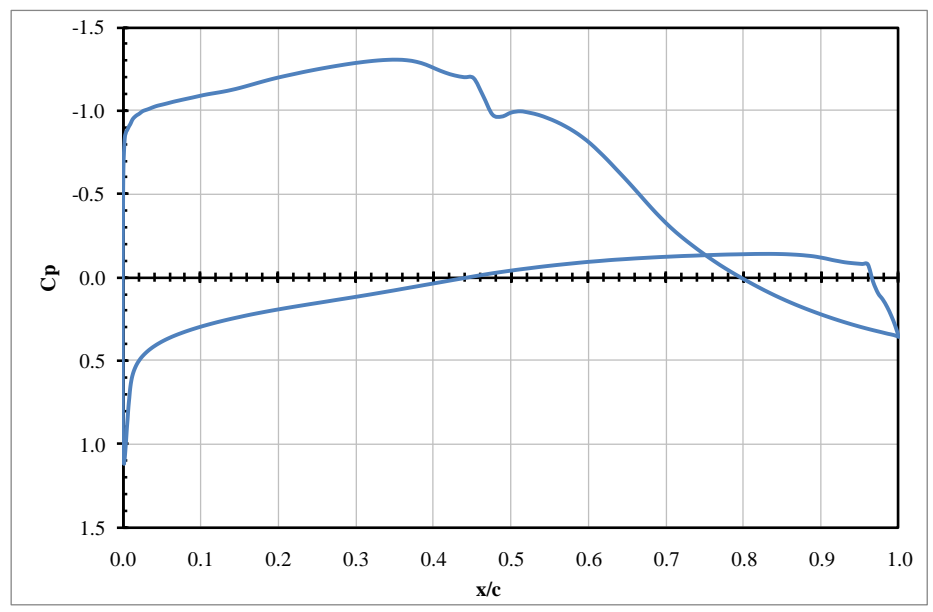

Figure 4. Laminar flow airfoil pressure distribution. 


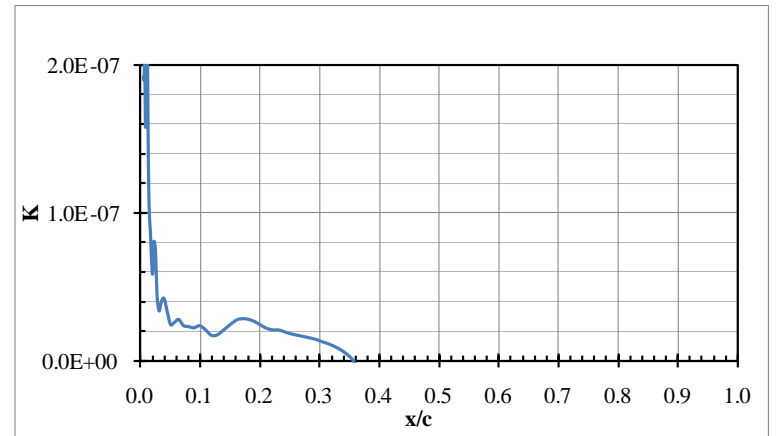

Figure 5. Upper surface dimensionless pressure gradient.

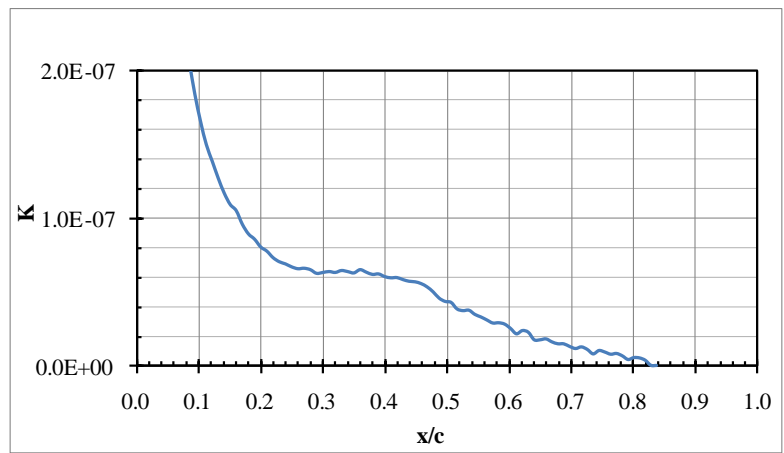

Figure 6. Lower surface dimensionless pressure gradient.

\section{Excrescence Testing for Pressure Gradient Effects}

To address the lack of detailed information on pressure gradient effects on the allowable excrescence sizes, a series of experimental studies was undertaken. The initial examination was conducted in a low-speed wind tunnel. This allowed an extensive number of pressure gradients to be examined, but was limited in Reynolds number range. ${ }^{7,8}$ The work was done in a low-speed wind tunnel with a 2 -ft by 2 - $\mathrm{ft}$ test section. The wind tunnel was designed for boundary layer research and was believed to have correspondingly good flow quality. The upper wall of the test section was flexible and designed to be positioned to create a streamwise pressure gradient in the test section. A flat plate model with a superellipse leading edge was used and the pressure gradient created by adjusting with wind tunnel upper wall. Integral to the test plate was an adjustable step. The highest transition Reynolds number that could be examined in this work was $1 \times 10^{6}$.

From this low-speed testing, transition locations were seen to vary in response to the local pressure gradient. Building on that earlier work, an approach to testing at higher Reynolds numbers was sought. This was complicated by the practical limitation of test facilities. The criteria for a test facility was the ability to obtain flight-representative Reynolds numbers with a low disturbance environment conducive to transition testing. The facility that was eventually identified and selected for this study was the Towing Wind Tunnel at Tohoku University's Sunrise Beach Research Facility in Hyuga, Japan. ${ }^{9}$ This facility was not a conventional wind

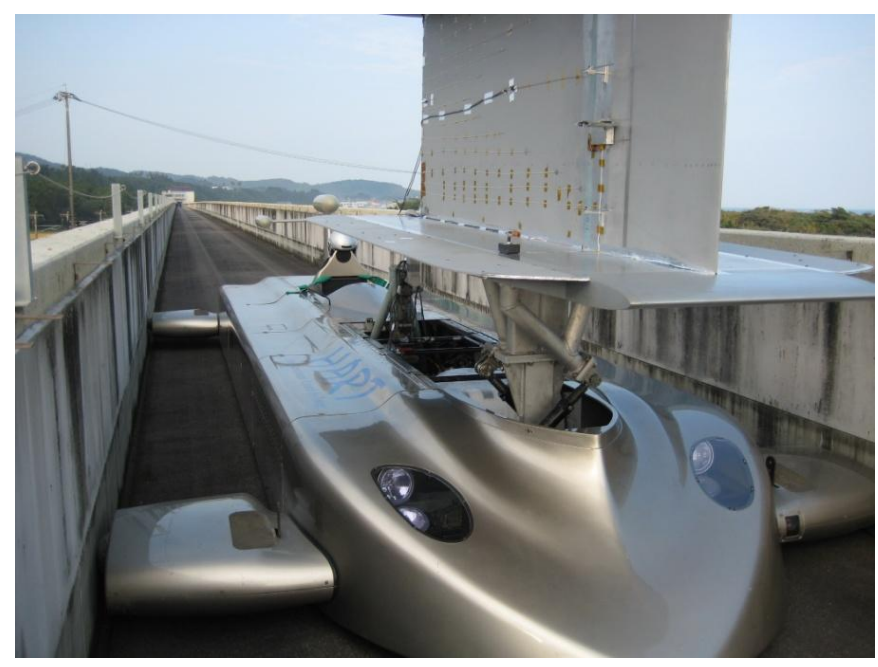

Figure 7. Towing Wind Tunnel carrier vehicle. tunnel, but rather a very long test track with an electric vehicle that carries the test model.

Because of the unique nature of the facility, it was necessary to have multiple models, each designed for a single specific pressure gradient. One of the models is shown installed on the carrier vehicle in figure 8 . The models featured an integral step, similar to that used on the test plate in the low-speed wind tunnel. Measurements were made of skin friction distributions to determine transition locations. ${ }^{10}$ Hot wire measurements were also performed. ${ }^{11}$ Measurements of the freestream disturbance environment were made; their interpretation was substantially complicated by the short (less than 30 seconds) run times possible with this facility.

Transition locations as a function of pressure gradient and step size were determined for transition Reynolds numbers as high as $5 \times 10^{6}$. This provides a Reynolds number range with significant overlap with high-altitude longendurance aircraft. From the measured skin friction distributions, transition locations were determined for each step tested. ${ }^{10}$ Both forward-facing and aft-facing steps were examined. The sizes of the steps were selected based on their observed influence on the transition location: small steps were initially tested, their heights increased until the 
transition location was moved forward from the no-step location, step height continued to be increased until the transition location was observed to be immediately downstream of the step.

Figures 8 through 11 show the results of this progressive testing of both forward- and aft-facing steps. The closed symbols on the plots show a measured transition location. Open symbols represent cases where the step was not observed to have any effect on the transition location.

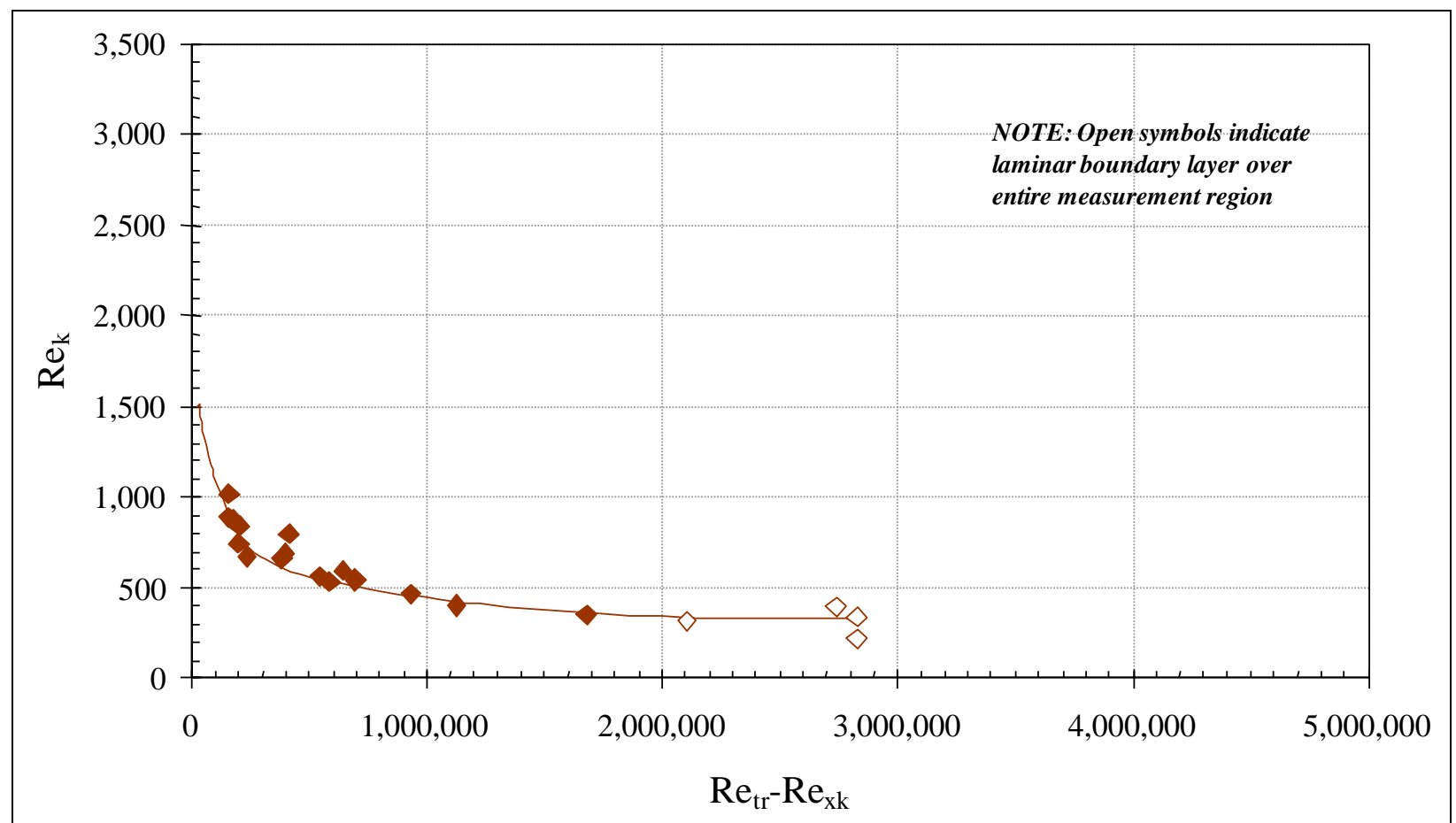

Figure 8. Aft-facing steps with a pressure gradient parameter, $\mathrm{K}$, of $0.2 \times 10^{-7}$.

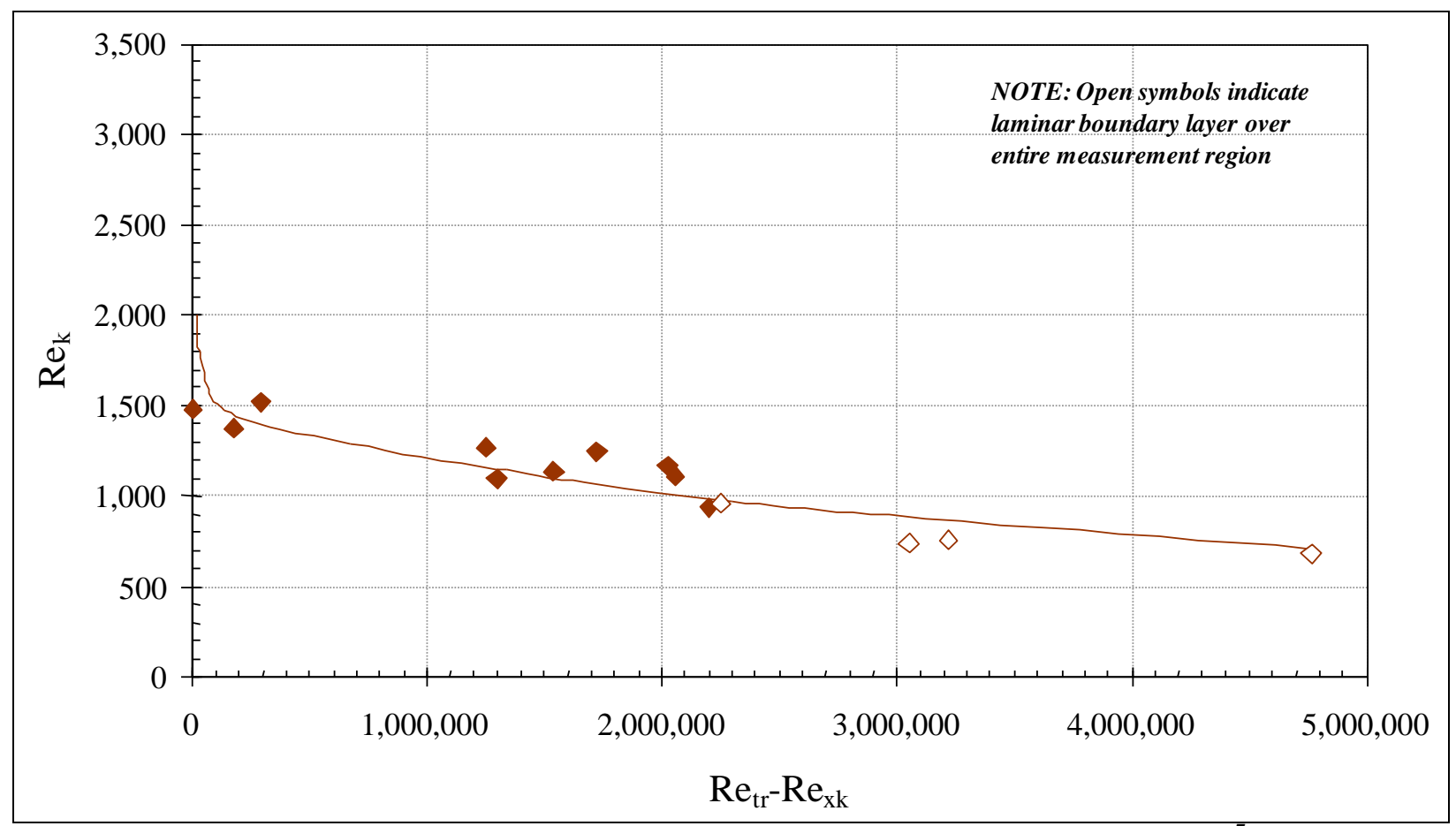

Figure 9. Aft-facing steps with a pressure gradient parameter, $\mathrm{K}$, of $0.5 \times 10^{-7}$.

American Institute of Aeronautics and Astronautics 


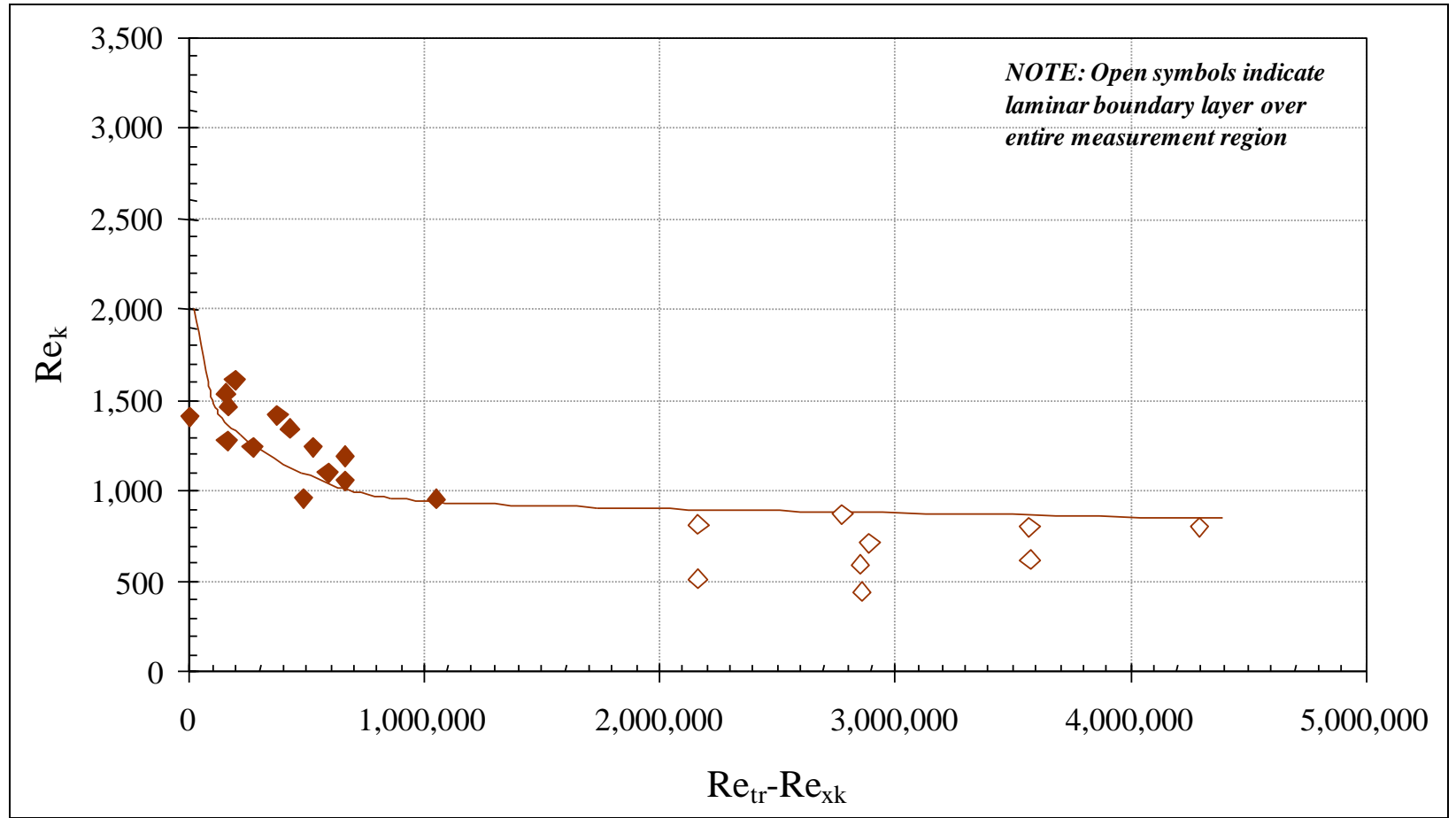

Figure 10. Forward-facing steps with a pressure gradient parameter, K, of $0.2 \times 10^{-7}$.

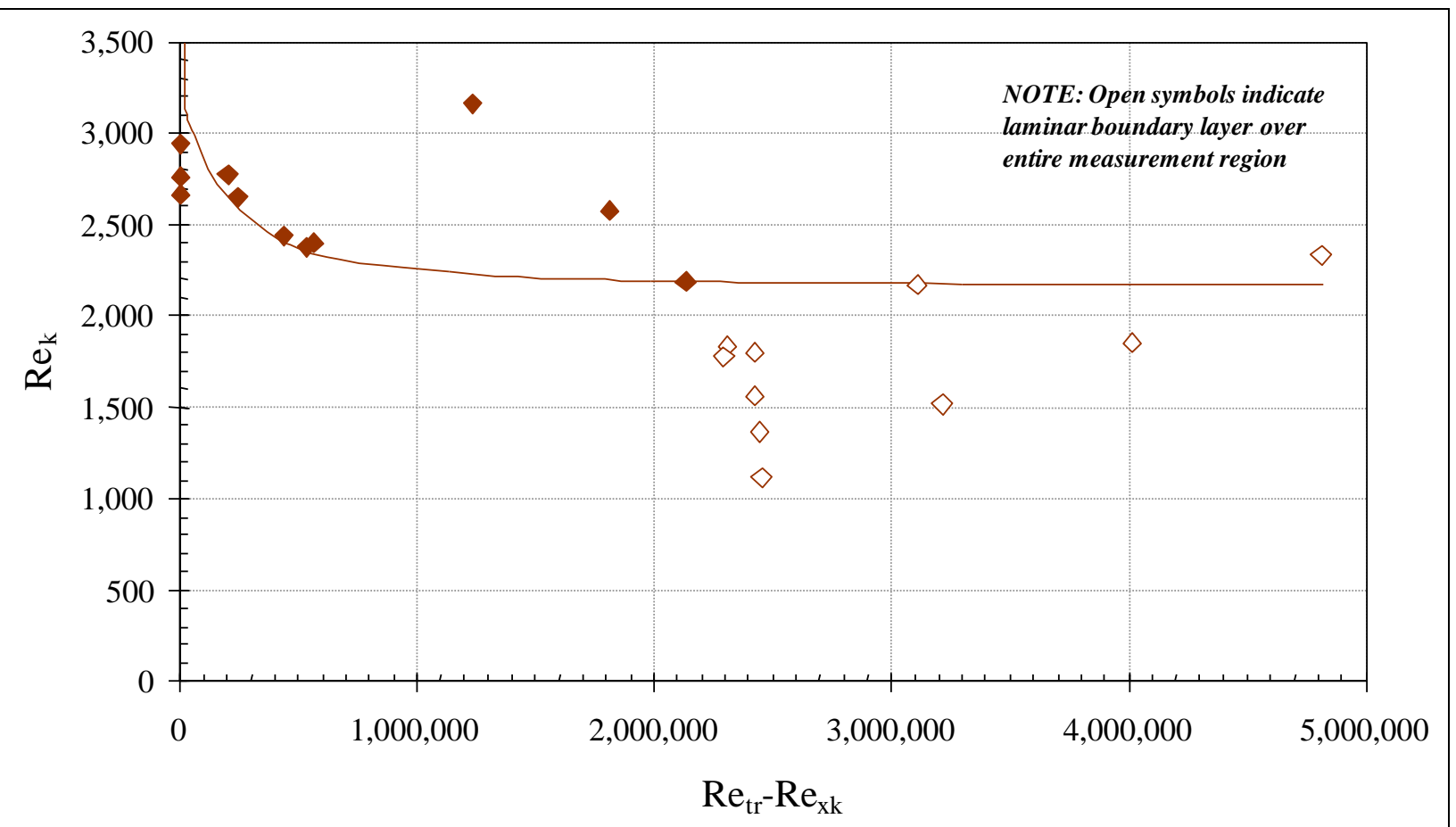

Figure 11. Forward-facing steps with a pressure gradient parameter, $\mathrm{K}$, of $0.5 \times 10^{-7}$.

For each of the two pressure gradients examined $\left(\mathrm{K}=0.2 \times 10^{-7}\right.$ and $\left.\mathrm{K}=0.5 \times 10^{-7}\right)$, clear trends in the forward movement of transition with increasing step height were observed. With these results, it was possible to identify a trend in this movement of transition; the result is shown as a line on the plots of figures 8-11. Comparisons of the trend lines between the two pressure gradients show a substantial stabilizing effect from increases in favorable pressure gradient.

American Institute of Aeronautics and Astronautics 


\section{Recommendations}

Assessments of the practicality of utilizing laminar flow for long-endurance vehicles is often strongly dependent on the perceived difficulty of manufacturing. Based on the results of recent testing, the conventional assumptions on the required manufacturing tolerances may be overly stringent in many situations. Initial low-speed wind tunnel testing showed that $\mathrm{Re}_{\text {krrit }}$ is a clear function of dimensionless pressure gradient, $\mathrm{K}$. Testing in the novel propelledmodel facility has extended these results to significantly higher Reynolds numbers. These relations are applicable to current and future laminar flow aircraft and can be used as a basis for determining the required manufacturing

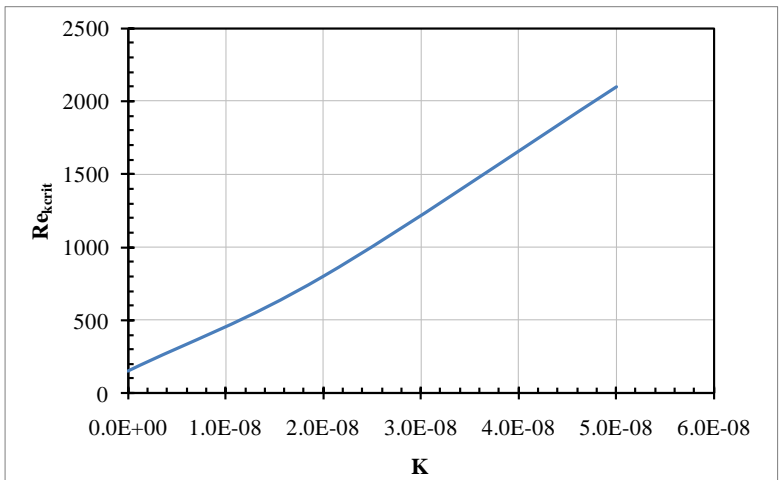

Figure 12. Forward-facing step critical excrescence Reynolds numbers.

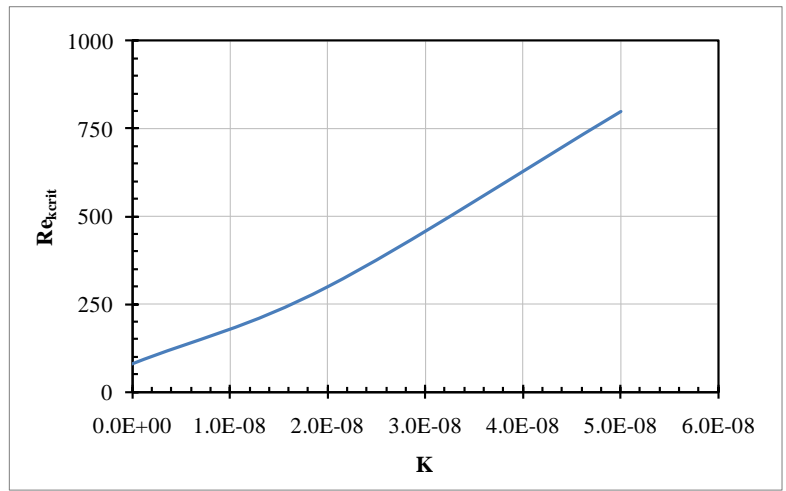

Figure 13. Aft-facing step critical excrescence Reynolds numbers.

tolerances. The allowable heights of step excrescences obtained in this study are significantly larger than previous studies have indicated. This will allow for loosening of tolerances on laminar flow aircraft which could contribute to more practical applications of the technology.

Figures 12 and 13 show recommended $\mathrm{Re}_{\text {kcrit }}$ values as a function of $\mathrm{K}$. To make use of these relations, the local $\mathrm{K}$ should be calculated as a function of chordwise location for the wing of interest, at all flight conditions that laminar flow is expected (note, off-design conditions for which the boundary layer is not expected to be laminar, need not be considered). Applying these relations, it is possible to determine the critical excrescence height for forward and aft-facing steps for a long-endurance aircraft. Figures 14 and 15 show the result, compared with the critical heights determined using the conventional approach that relied on flat-plate data. It indicates that the allowable heights could be as much as four times greater than conventionally believed.

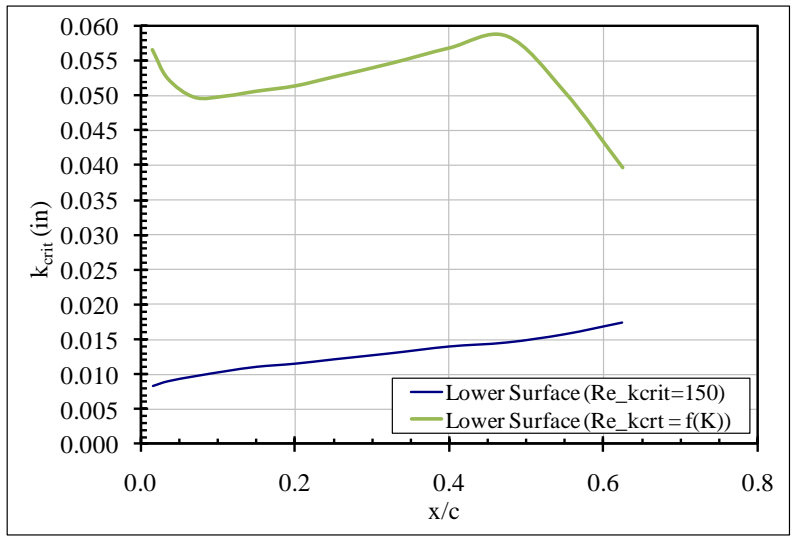

Figure 14. Forward-facing step critical heights for a long-endurance aircraft.

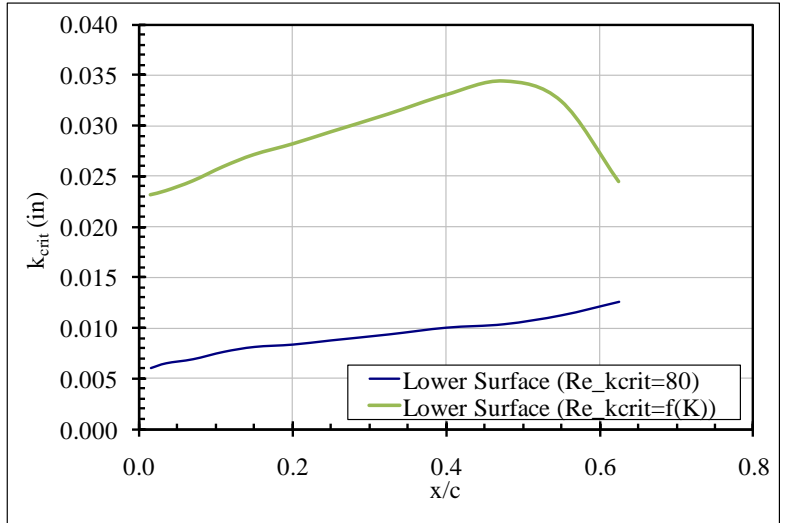

Figure 15. Aft-facing step critical heights for a long-endurance aircraft. 


\section{Acknowledgments}

This work was sponsored by the U.S. Air Force Research Laboratory, Air Vehicles Directorate.

\section{References}

${ }^{1}$ Fage, A., "The Smallest Size of a Spanwise Surface Corrugation which Affects Boundary-Layer Transition on an Aerofoil," RAE R\&M 2120, January 1943.

${ }^{2}$ Drake, A., Westphal, R. V., Zuniga, F. A., Kennelly, R. A., and Koga, D. J., "Wing Leading Edge Joint Laminar Flow Tests," NASA TM 4762, 1996.

${ }^{3}$ Driver, D. M., and Drake, A., "Skin Friction Measurements Using Oil Film Interferometry in the 11' Transonic Wind Tunnel at Ames," AIAA-2004-1359, 42 ${ }^{\text {nd }}$ AIAA Aerospace Sciences Meeting, Jan. 2004.

${ }^{4}$ Braslow, A. L., "Review of the Effect of Distributed Surface Roughness on Boundary Layer Transition" AGARD Report 254, 1960.

${ }^{5}$ Smith, A. M. O., and Clutter, D. W., "The Smallest Height of Roughness Capable of Affecting Boundary-Layer Transition in Low-Speed Flow" Douglas Aircraft Co. Engineering Report ES 26803, 1954.

${ }^{6}$ Hood, M. J., "The Effects of Surface Waviness and of Rib Stitching on Wing Drag" N.A.C.A. Technical Note No. 724, Aug. 1939.

${ }^{7}$ Bender, A. M., Bleazard, M., Westphal, R. V., Vavra A. J., and Drake, A., "An Approach to Measuring the Effects of Surface Excrescences on Transition in the Presence of Arbitrary Pressure Gradients," ICIASF'05 Record, IEEE Catalog No. 05CH37670C, pp. 143-151, 2005.

${ }^{8}$ Drake, A., Bender, A. M., Solomon, W. J., and Vavra, A. J., “Air Vehicle Technology Integration Program (AVTIP) Delivery Order 0020: Prediction of Manufacturing Tolerances for Laminar Flow Final Report," AFRL-VA-WP-TR-2005-3060, June 2005.

${ }^{9}$ Yoshioka, Kikuchi, Ohta, Kato, Song, and Kohama, "Measurement of ground effect and boundary-layer transition by towing wind tunnel," 2009 Fluid Dyn. Res. 41021408 (12pp).

${ }^{10}$ Bender, A. M., Elliott, J. R., Shinagawa, Y., Korntheuer, A. J., Drake, A., Westphal, R. V., Gerashchenko, S., McKeon, B. J., and Yoshioka, S., "An Approach to Measuring Step Excrescence Effects in the Presence of a Pressure Gradient," AIAA-2010373, 48th AIAA Aerospace Sciences Meeting, Jan. 2010.

${ }^{11}$ Gerashchenko, S., McKeon, B. J., Westphal, R. V., Bender, A. M., and Drake, A., "Hot-Wire Measurements of the Influence of Surface Steps on Transition in Favorable Pressure Gradient Boundary Layers," AIAA-2010-374, 48th AIAA Aerospace Sciences Meeting, Jan. 2010. 